\title{
Assessment of agroclimatic suitability of apple orchards in Himachal Pradesh under changing climate
}

\author{
JYOTI SINGH and N. R. PATEL* \\ Indian Institute of Remote Sensing, ISRO, Dehrdaun - 248001 \\ *Corresponding author E mail : pnatoo@gmail.com
}

\begin{abstract}
Apple crop require adequate chilling for breaking its winter dormancy for a usual spring growth. In this study, suitability of apple production was assessed by using GIS based UTAH chill unit model for tactical and strategic adaptation options under changed climatic scenarios. This analysis consists of spatial chilling zonation from year 1978-2013, delineation of suitability classes for apple production based on effective chill units(ECU), and shift in apple belt in Himachal Pradesh under changing climate. The result showed spatial extent of chilling zone having ECU>1500 has declined. The traditional apple crop areas are shifting upward in Himachal Pradesh as a result less suitable areas transforming in unsuitable and severely cold areas which were earlier not suitable are becoming suitable for apple cultivation.
\end{abstract}

Key words : Agroclimatic suitability, apple productivity, chilling requirement, GIS, ECU, chilling zonation

Apple is the fourth important fruit crop of India after Mango, Citrus and Banana. Himachal Pradesh is the second largest producer of apple after Jammu and Kashmir (Chadha, 2001). Apple cultivation is economically rewarding which helps in boosting financial status of farmers and provides them better standards for living in Himachal Pradesh. Recently impact of global climate change on agriculture has been reported as one of the alarming phenomenon and Himalayas are among those region which will witness rapid climate change causing severe damage to environment, economics and society of Himalaya and its habitants (Chaudhary and Bawa, 2011). The observed climatic trends over northwestern Himalayas showed a significant increasing in mean and maximum temperature over time period of 1951-2010 (Rathore et al., 2013). Adverse impact of climate change in Western Himalayas on apple producing areas and productivity is being reported in recent decades (Rana et al., 2009; Chaudhary and Bawa, 2011; Basannagari and Kala, 2013). Kullu valley the apple belt of state has gone under sharp decline of apple productivity and apple orchards had been replaced by vegetables and fruit varieties (with lower chilling requirements) in several areas. The increase in minimum temperature was more for the lower elevation areas (below $700 \mathrm{~m}$ amsl) as compared to higher elevation areas (Rana et al. 2012).Hence, areas at higher altitudes are becoming more suitable for apple cultivation like Lahaul and Spiti (Rana et al., 2011). Apple cultivation is being replaced by other stone fruits in lower altitudes and expanding towards upper altitudes (Rana et al., 2009).

The temperature trends in apple growing regions of Kullu and Shimla districts of Himachal Pradesh indicated 1.8 to $4.1^{\circ} \mathrm{C}$ rise in past few decades which reflected in decrease of effective chill units (ECU) hours accumulations (Rana et al., 2011).Addressing the negative impacts of warming on deciduous fruits, a comprehensive and spatially distributed information on chilling requirements from chill unit models are crucial (Luedeling and Brown, 2011). In this study, a geographical information system (GIS) was employed to map spatial extent of chilling zones under changing climate based on the principles of UTAH chill unit model. Chilling zones were later used to delineate suitable classes for apple cultivation and shift in apple belt over Himachal Pradesh.

\section{MATERIALS AND METHODS}

\section{Climate data and processing}

The gridded climatic data from 1969 to 2013 were obtained from National Climate Centre, India Meteorological Department (IMD).From this, the temperature and precipitation data for Himachal Pradesh region were extracted. After extraction $1 \times 1$ degree gridded daily temperature data contains $4 \times 5$ grid points. The latitude ranges from $29.5^{\circ}$ to $33.5^{\circ} \mathrm{N}$ having 4 grids and longitude ranges from $74.5^{\circ}$ to $79.5^{\circ} \mathrm{E}$ having 5 grids. The precipitation data at $0.25 \times 0.25$ degree grid covers daily precipitation data contains $14 \times 16$ grid points. Its latitude ranges from $30^{\circ}$ to $33.5^{\circ} \mathrm{N}$ having 14 grids and longitude ranges from $75.25^{\circ}$ 
Table 1: Conversion of selected temperatures to chill unit factors for the UTAH model

\begin{tabular}{ll}
\hline Temperature $\left({ }^{0} \mathrm{C}\right)$ & Chill unit factor $\left(\mathrm{C}_{\mathrm{U}}\right)$ \\
\hline$<1.5$ & 0.0 \\
$1.5-2.4$ & 0.5 \\
$2.5-9.1$ & 1.0 \\
$9.2-12.4$ & 0.5 \\
$12.5-15.9$ & 0.0 \\
$16.0-18.0$ & -0.5 \\
$>18.0$ & -1.0 \\
\hline
\end{tabular}

Table 2: Suitability classes for apple cultivation and accumulated chilling units

\begin{tabular}{ll}
\hline Suitability class & $\mathrm{C}_{\mathrm{U}}$ \\
\hline Highly suitable & $800-1000$ \\
Moderately suitable & $600-800$ and 1000-1500 \\
Marginally suitable & $300-600$ \\
Not suitable & $<300$ and $>1500$ \\
\hline
\end{tabular}

to $79.25^{\circ} \mathrm{E}$ having 16 grids. October to March time scale were considered for calculating effective chill units (ECU).

\section{GIS based UTAH chill unit model}

A simple GIS based chill unit model was developed to calculate ECU (effective chill unit) grid based and grid size adopted is same as input data grid size. The hourly temperature were derived from daily maximum and minimum temperatures assuming $12 \mathrm{~h}$ day with maximum temperature occurring at $2 \mathrm{PM}$ and minimum temperature at $2 \mathrm{AM}$ with linear increase from 2 AM to 2 PM and decrease from 2 PM to $2 \mathrm{AM}$. UTAH chill unit model (Richardson et al., 1974)which takes into account the concept of negative and positive chilling was considered. According to the UTAH model most effective temperature range which contributes in dormancy release is between 1.5 and $12.4{ }^{\circ} \mathrm{C}$. Chill unit was calculated on hourly basis by multiplying the hourly temperature with chill unit factors (Table 1) and accumulated for whole season. Thus the effective chill unit (ECU) for whole season (October to March) was determined.The ECU were grouped into 7 classes of chill zones, viz. $<0,0-300,300-60,600-800,800$ $1000,1000-1500$ and $>1500$ and mapped using GIS. Further, suitability classification for apple cultivation were done as per criteria given in Table 2 .

\section{RESULTS AND DISCUSSION}

\section{Spatial assessment of various chilling zones}

Inter-annual variation in ECU over Himachal Pradesh

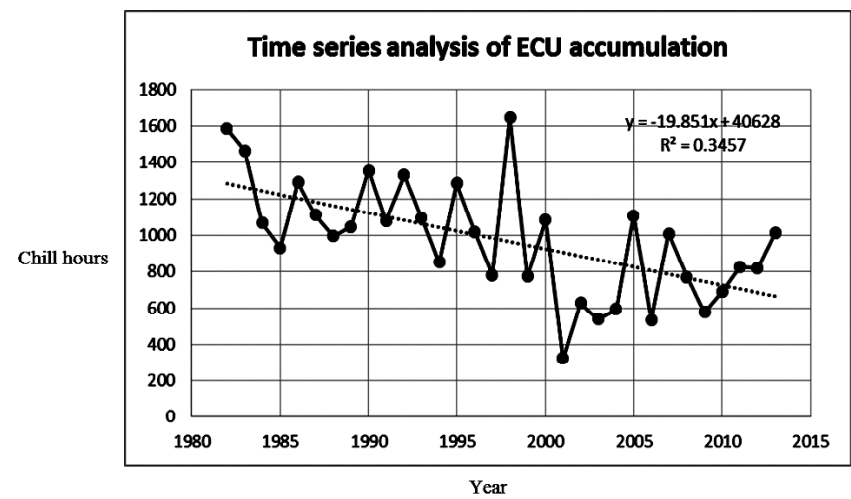

Fig. 1: Time series analysis of ECU for apple in Himachal Pradesh from 1982-2013

indicated a decreasing trend over a period of 1978 to 2013 and quite irregular during the period of 2000-2013 (Fig.1). For detecting shift in chill zones as impact of climate change, the ECU averaged for every decade depicts a clear picture of variation in spatial pattern of various chill zones over each decade. Fig. 2 indicates various chill unit zones for different decades; viz. 1978-1986, 1987-1995,1996-2004 and 20052013. The map shows how spatial extent of chilling zone having $\mathrm{C}_{\mathrm{U}}>1500$ diminished (Fig. 2 IV). The zone of ideal chill unit requirement (i.e. $1000<\mathrm{C}_{\mathrm{U}}<1500$ ) is shifting towards higher elevation (areal extent decreases from 13643 to $5125.1 \mathrm{~km}^{2}$ in last decade) along with other chilling zones. As a result, the area under chilling $\mathrm{C}_{\mathrm{U}}<0$ increased progressively from first to fourth decade. The area having chill unit less than zero has increased from $14482.4 \mathrm{~km}^{2}$ (Fig.2-I) to $26576 \mathrm{~km}^{2}$ (Fig.2-IV). Which is almost twice the area in the first decade. The shift in zones towards higher elevation was marginal in early decades but the rate of change increased drastically in third decade and reached to the highest in fourth decade. This reflect the spatial extent under $1000<\mathrm{C}_{\mathrm{U}}<1500$ in fourth decade similar to spatial extent under $\mathrm{C}_{\mathrm{U}}>1500$ of first decade.

\section{Apple suitability based on ECU}

The suitability assessment for apple was done on the basis of the chilling requirements which clearly reflect the importance of winter temperatures. Parts of Kullu, Chamba, Kangra, Lahaul \& Spiti and Kinnaur districts comes under highly suitable zone in first decade but in fourth decade (Fig. 3-IV) Kullu and Kangra districts switch over to other classes. The moderately suitable class consists of parts of Chamba, Kangra, Kullu, Lahual \& Spiti and Kinnaur districts below highly suitable zone and parts of Chamba, Lahaul \& Spiti districts above highly suitable zone up to third decade (Fig. 3-III). Marginally suitable class contains single chilling 

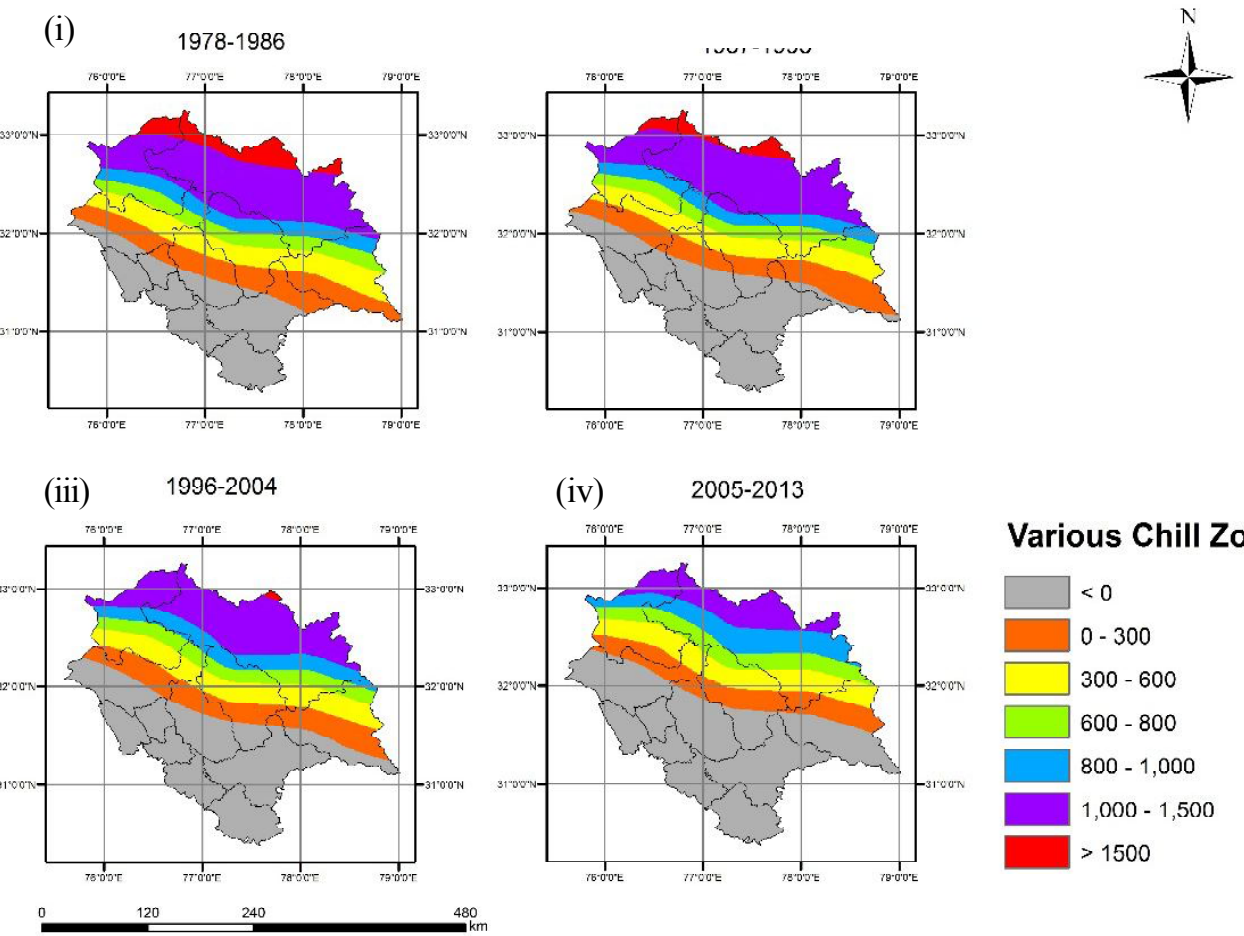

Fig.2: Spatial extents of various chilling zones under changing climate
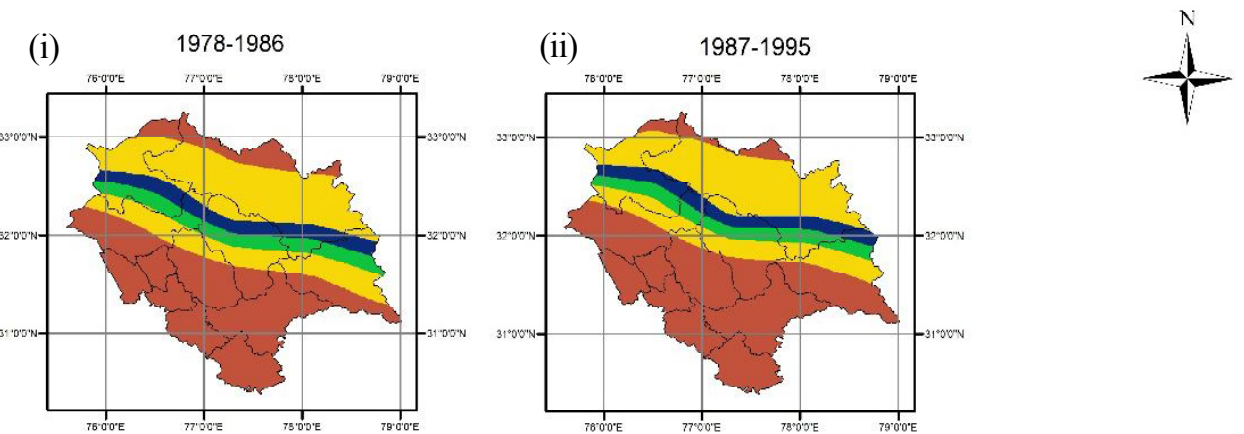

(iii)
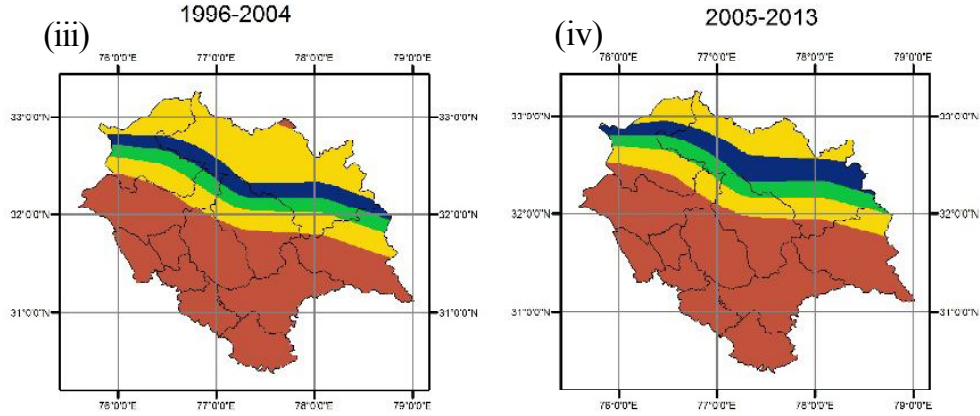

Suitability Classes
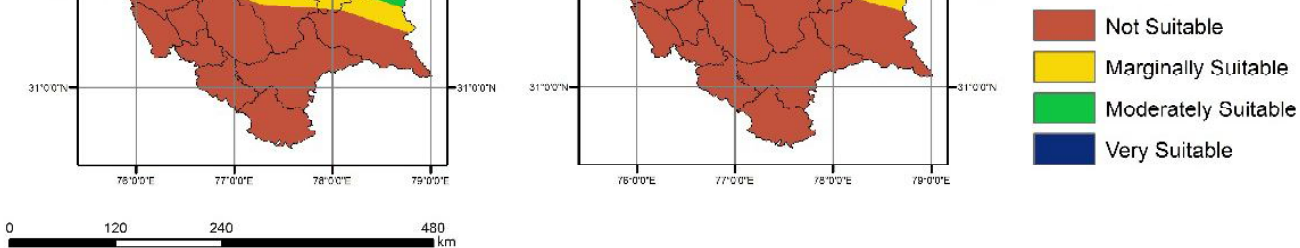

Fig.3: Suitable classes for practicing apple cultivation in Himachal Pradesh, India

zone (300-600) which is below moderately suitable zone. This area has shifted upwards causing low elevation areas to become unsuitable with the time. Not suitable areas contained two classes as given in Table 2 . The area under $\mathrm{C}_{\mathrm{U}}>1500$ decreased rapidly from first to second as well as third decade and finally become nil in recent decade (Fig.3). Whereas, the not suitable zone with $\mathrm{C}_{\mathrm{U}}<300$ increased continuously from first to fourth decade as evidence from more than half of the 
area in Kullu district occupied by this zone.

This shift of suitable area towards higher altitudes is very much evident in Kullu district, lower lying areas which had been producing good quality apples in earlier decades are no longer viable due to lowering of fruit quality and are replaced mostly by vegetables and fruits having low chill requirement (Vedwan and Rhoades, 2001). Himachal Pradesh has lot of potential to expand the production of various deciduous fruits and nuts in to regions becoming relatively warmer for production of apple. The chill zone with chill unit between 0-300 are not suitable for apple but few cultivars requiring up to 200 chill hour such as low chill almonds can be cultivated successfully. Likewise chill zones with chilling hours between 300-600 are suitable for growing apples with low chill requirement and apart from this species having similar chill requirements can be cultivated in these zones.

\section{CONCLUSIONS}

The study concluded that apple belt is shifting from lower to higher elevation areas on account of non-optimal availability of chilling unit requirement. Total suitable area for apple production decreased from 53 per cent to 39.9 per cent of the state. As result apple varieties with high winter chill requirement has to be replaced with low chill apple varieties. For maintaining and planning orchards more accurate estimation of winter chill is required and to achieve these region specific chill models based on climate of the region should be used.

\section{REFERENCES}

Basannagari, B. and Kala, C. P. (2013).Climate Change and Apple Farming in Indian Himalayas:A Study of Local Perceptions and Responses. PLoS ONE, 8(10):1-6.

Cesaraccio, C., Spano, D., Snyder, R. L. and Duce, P. (2004). Chilling and forcing model to predict bud-burst of crop and forest species. Agric. Forest Meteorol., 126(1): 113.

Chadha, K. L. (2001). "Handbook of horticulture”. Directorate of Information and Publications of Agriculture, Indian Council of Agricultural Research, New Delhi

Chaudhary, P. and Bawa, K. S. (2011). Local perceptions of climate change validated by scientific evidence in the Himalayas. Biology Letters : 1- 4.DOI: 10.1098/ rsbl.2011.0269.

Luedeling, E. and Brown, P. H. (2011). Aglobal analysis of the comparability of winter chill models for fruit and nut trees. Intern. J. Biometeorol. 55(3): 411-421.

Rathore, L.S., Attri, S.D. and Jaswal, A.K. (2013). State level climate change trends in India.Meteorological Monograph No. ESSO/IMD/EMRC/02/2013, India Meteorological Department.

Rana, R. S., Bhagat, R. M., Kalia, V. and Lal, H. (2009). Impact of climate change on shift of apple belt in Himachal Pradesh. In : Proceedings of the workshop on Impact of Climate Change on Agriculture, pp. 17-18. Space Applicaion Centre, Ahmedabad.

Rana, R. S., Bgagat, R. M. andKalia, V.(2011). Impact of climate change on apple crop in Himachal Pradesh. Agrometeorol., 13 (2): 97-103.

Rana, R. S., Bgagat, R. M. and Kalia, V., Singh, S. and Prasad, R. (2012). Trends in climate variability over Himachal Pradesh. J. Agrometeorol., 14 (1) : 35-40.

Richardson, E.A., Seeley, S. D. and Walker, D. R. (1974).Amodel for estimating the completion of rest for Redhaven and Elberta peach trees. Hort. Sci., 10:236-332.

Vedwan, N. and Rhoades, R. E. (2001). Climate Change in the Western Himalayas of India: AStudy of Local Perception and Response. Climate Res., 19: 109-117. 